\title{
O massacre dos estudantes na cidade do México em 1968: o poeta Octavio Paz e a história política ${ }^{1}$
}

\author{
Ival de Assis Cripa ${ }^{2}$
}

Resumo: O artigo analisa o ensaio Posdata e reflete sobre os temas da violência e do autoritarismo na obra do poeta mexicano Octavio Paz. Trata-se de um ensaio que foi escrito como um ato de repúdio contra o massacre e o desaparecimento dos corpos de mais de trezentos estudantes, praticado pelo Exército Federal na cidade do México no dia 2 de outubro de 1968. Discute-se o posicionamento do poeta no espaço público recuperando as suas reflexões sobre a violência e o autoritarismo do Estado mexicano, durante a hegemonia do Partido Revolucionário Institucional (PRI).

Palavras-chave: história política, literatura, Octavio Paz, violência, México.

\begin{abstract}
The article analyzes the essay Postdata and reflects on the violence and authoritarianism themes in the work of the Mexican poet Octavio Paz. It is an essay written as an act of repudiation against the massacre and the disappearance of the bodies of over 200 students, killed by the Federal Army in Mexico City on $2^{\text {nd }}$ October, 1968. It discusses the position of a poet in the public arena and recovers his reflections on the violence and authoritarianism of the Mexican State during the hegemony of the Institutional Revolutionary Party.
\end{abstract}

Keywords: political history, literature, Octavio Paz, violence, Mexico.

No ensaio Posdata, Octavio Paz denunciou a violência do governo mexicano contra os estudantes em outubro de 1968, ao ordenar que o exército reprimisse brutalmente os estudantes que reivindicavam reformas democráticas na universidade e na sociedade mexicanas. As vítimas somam mais de trezentos mortos, cujos corpos não foram encontrados até hoje. ${ }^{3}$ Quando o massacre ocorreu, Octavio Paz era embaixador

\footnotetext{
${ }^{1}$ Este artigo é parte da tese de doutorado sobre os ensaios de Octavio Paz, defendida em 2007 na área de Teoria e História Literária no Instituto de Estudos da Linguagem da UNICAMP.

${ }^{2}$ Doutor em Teoria e História Literária do Instituto de Estudos da Linguagem da UNICAMP, e professor de História da América Latina da Faculdade de História do Centro Universitário UNIFIEO e das Faculdades Integradas de Guarulhos. E-mail para contato: ivaldeassis@ yahoo.com.br .

${ }^{3}$ Segundo Silvia Cezar Miskulin, "o número de estudantes, homens, mulheres e criança mortas continuam ainda hoje desconhecidos. Segundo o periódico The Guardian 325 pessoas foram assassinadas na Praça das Três Culturas. O governo reconheceu oficialmente 35 mortos, sendo que apenas 2 soldados entre os
}

Revista Eletrônica da ANPHLAC, n.11, p. 40-58, jul./dez. 2011.

http://revista.anphlac.org.br/index.php/revista 
na Índia e, como protesto contra a morte dos estudantes, demitiu-se do cargo e rompeu com o governo do PRI, passando a criticar abertamente o regime de partido único vigente no México desde a criação do Partido Nacional Revolucionário (PNR), em 1929. Na presidência de Lázaro Cárdenas (1934-1940), o nome do partido mudou para Partido Revolucionário Mexicano (PRM) em 1937, e, em 1946, tornou-se Partido Revolucionário Institucional (PRI). ${ }^{4}$

O repúdio de Octavio Paz à violência do Estado pode ser interpretado como um envolvimento político ao estilo dos intelectuais franceses, que, desde o manifesto de Zola "Eu acuso" em defesa de Dreyfus, inauguraram um tipo diferente de "engajamento" contra as várias formas de violência praticadas sempre em nome das "razões de Estado". Segundo Benoît Denis, ao engajar-se, um escritor decide ir ao encontro das exigências do tempo presente: "Ele deseja que sua obra aja aqui e agora e ele aceita, em compensação que ela seja situada, legível num contexto limitado e, portanto, ameaçada por uma obsolescência rápida". $\mathrm{O}$ ensaio, tal como o romance, o manifesto e o teatro, a partir de Malraux, Camus e Sartre, tornou-se uma forma de engajamento:

Concebe-se desde então que o ensaio seja um gênero de predileção para o escritor engajado: ele se arrisca inteiro no seu texto, ancorando as suas tomadas de posição no concreto de uma relação com o mundo pessoal (...) Através do ensaio dá-se assim para ver essa 'presença total do autor na escritura', que é a condição primeira do engajamento. ${ }^{6}$

As abordagens mais recentes da história política e da história intelectual podem ajudar a compreender melhor a intervenção do poeta mexicano no campo político após a repressão aos estudantes em 1968. Para Pierre Rosanvallon, por exemplo, o tema do engajamento dos intelectuais, no âmbito da história política, precisa ser entendido como

mortos, o que demonstrou na opinião de Eliana Poniatowska (1977, p. 20) que os tiros se dirigiram contra os manifestantes e não contra os soldados". MISKULIN, Silvia Cezar. A repercussão do Movimento Estudantil de 1968 no México. In: Encontro Internacional da ANPHLAC, 8., 2008, Vitória, Anais eletrônicos... Vitória: ANPHLAC, 2008. p. 5.

${ }^{4}$ O Partido Nacional Revolucionário foi criado em 1929, sob o comando do general Plutarco Elias Calles, “Chefe Máximo" da Revolução. O partido surgiu, assim, no contexto da vitória da facção burguesa sobre os exércitos de Villa e Zapata e quando o general Calles buscava "estabilizar" o regime e acabar com os conflitos internos entre os líderes da facção burguesa pelo poder. Após a eleição de Lázaro Cárdenas, em 1934, o partido mudou de nome para Partido Revolucionário Mexicano em 1937. Em 1946, passou a se chamar Partido Revolucionário Institucional e tornou-se um partido hegemônico no sistema eleitoral mexicano por mais de 70 anos, quando supostamente sua hegemonia pode ter terminado com a eleição de Vicente Fox pelo Partido da Ação Nacional (PAN) no México em 2000?

${ }^{5}$ BENOÎT, Denis. Literatura e engajamento: de Pascal a Sartre. Bauru: EDUSC 2002, p. 94.

${ }^{6}$ Ibid., p. 94.

Revista Eletrônica da ANPHLAC, n.11, p. 40-58, jul./dez. 2011. http://revista.anphlac.org.br/index.php/revista 
uma forma diferente de compromisso: "De certo modo, é a própria natureza do trabalho intelectual que produz esse novo comprometimento político (...). O conhecimento tornase então uma forma de ação, que torna o trabalho intelectual per si uma forma de prática política". 7

Octavio Paz, ao publicar Posdata, interferiu na cena política mexicana e buscou explicar a violência do Estado a partir da recuperação da história mexicana desde o período anterior à conquista espanhola, ou seja, procurou entender um acontecimento situado em seu tempo presente a partir da reflexão sobre o passado do país. De uma perspectiva interdisciplinar, podemos considerar que o percurso de Paz e dos poetas em geral, cujo ofício, segundo Rosanvallon, é "explorar as palavras e tentar dominar a realidade opaca por meio da linguagem", se cruza com o dos historiadores "do político" preocupados em apreender o movimento da democracia. Desse modo, ao menos para Rosanvallon, poetas e historiadores são ambos decifradores dos mitos e enigmas que constituem a história política:

\begin{abstract}
Se a literatura e a poesia têm por finalidade nos abrir o mundo pelo meio instável das palavras, ambas encontram, com efeito, no interior das incertezas da era democrática, uma nova razão de ser. O romancista e o poeta, cada qual ao seu modo, são topógrafos das ambigüidades e os decifradores de silêncios, permanecendo abertos às contradições do mundo sem jamais permitirem que o conceito exaura a substância da realidade. Desse modo, a história do político, tal como a literatura, trabalha nos interstícios das ciências sociais, que participam assim de movimento aparentado de decifração. Seria impossível, aliás, esquecer o lugar ocupado pela escrita em tantos historiadores do século XIX: através de sua linguagem e estilo, foi Michelet quem melhor soube dizer aquilo que, por vezes, seus documentos mal conseguiam explicar. ${ }^{8}$
\end{abstract}

Como um decifrador de enigmas ou de silêncios da história política, Octavio Paz buscou explicar a violência contra os estudantes no México em 1968 sem ficar preso ao âmbito das determinações ditadas pelas infraestruturas econômicas ou pelas superestruturas sociais e políticas. Sob essa perspectiva, criticada, aliás, por Paz, o massacre dos estudantes seria apenas uma mera consequência dos impasses criados pelo processo de modernização da sociedade mexicana. E, nesse caso, a violência do governo estaria relacionada a um processo mais amplo de "militarização do Estado" na América Latina. Sem desconsiderar tais argumentos, Octavio Paz chama a atenção para determinadas "coincidências", como o fato de o massacre dos estudantes ter ocorrido no

\footnotetext{
${ }^{7}$ ROSANVALLON, Pierre. Por uma história do político. São Paulo: Alameda, 2010, p. 54.

${ }^{8}$ Ibid.,p. 93. (grifos nossos)
}

Revista Eletrônica da ANPHLAC, n.11, p. 40-58, jul./dez. 2011.

http://revista.anphlac.org.br/index.php/revista 
mesmo local onde eram realizados os "sacrifícios" no Império Asteca. Paz recupera os traços de "longa duração" na história do México, que devem ser considerados na interpretação do massacre dos estudantes em 1968.

Para decifrar a dimensão ritual da vida política mexicana, Octavio Paz refere-se ao massacre na Praça de Tlatelolco utilizando o termo sacrifício, e ressalta que o ato de violência do exército sucedera no mesmo lugar em que se faziam os sacrifícios dos inimigos vencidos em guerra, dos escravos e dos membros dos grupos étnicos minoritários. Na verdade, os condenados ao sacrifício eram, em sua maioria, os povos dominados pelo Império Asteca, todos oferecidos a Quetzalcoaltl, Deus dos Astecas, representado por uma serpente emplumada. ${ }^{9}$ Ao interpretar a violência do Estado mexicano, Octavio Paz estabelece, portanto, uma ligação entre o passado histórico e um acontecimento presente. Em "Posdata", Paz recuperou as teses do Labirinto da Solidão, mas com algumas mudanças de posição importantes, ao romper de vez com a "fillosofia do mexicano" $" 10$ e com um conjunto de obras que refletiram sobre a identidade mexicana. Obras que, na verdade, serviram de base ideológica para o discurso nacionalista do grupo hegemônico, encarnado no Partido Revolucionário Institucional.

Para Octavio Paz, o movimento estudantil no México, de modo análogo aos movimentos mundiais ocorridos em 1968, possuiu um caráter universal, pois, em Praga, Chicago, Paris, Tóquio, Roma e no México, a rebelião juvenil anulou certas classificações ideológicas. Em muitos casos, como o da França, o movimento estudantil não contou com o proletariado, considerado a priori a classe revolucionária. No México houve, segundo Paz, algumas curiosas coincidências. O Partido Comunista Francês e o governo mexicano acreditavam que os movimentos estudantis, tanto em Paris como na

\footnotetext{
${ }^{9}$ Sem dúvida, ao acompanhar pela imprensa os dados sobre a violência hoje no México, acreditamos que suas causas sejam as mesmas da violência em outras metrópoles latino-americanas, tais como as desigualdades sociais e a ausência de políticas públicas. Porém, alguns traços específicos da violência no México talvez possam ser mais bem compreendidos se nos ativermos às colocações de Octavio Paz, por exemplo, sobre a violência ritual mexicana.

${ }^{10} \mathrm{O}$ tema do nacionalismo é recorrente na obra de Octavio Paz, mas precisamos tomar cuidado com as generalizações. Em uma carta destinada a Alfonso Reyes, datada de 23 de novembro de 1949, ele afirma: "le confieso que el tema de México - así impuesto, por decreto de cualquier imbécil convertido en oráculo de la 'circunstancia' y el 'compromiso' - empieza a cargarme. Y si yo mismo recurrí en un libro fue para liberarme de esa enfermedad - que sería grotesca si no fuera peligrosa y escondiera un deseo de nivelarlo todo. Un país borracho de sí mismo (en una guerra o en una revolución), puede ser un país sano, pletórico de su substancia o en busca de ella. Pero esa obsesión en la paz revela un nacionalismo torcido, que desemboca en agresión si es fuerte y en narcisismo y masoquismo si se es miserable como ocurre entre nosotros". Correspondencia Alfonso Reyes-Octavio Paz (1939-1959), citado por MONSIVAIS, Carlos. El Laberinto de la Soledad: el juego de espejos. Memoria del Coloquio Internacional "Por el Laberinto de la soledad a 50 años de su publicación". Anuário da Fundación Octavio Paz, n. 3, Fundación Octavio PazlEFE: Ciudad de México, p. 21, 2001.
}

Revista Eletrônica da ANPHLAC, n.11, p. 40-58, jul./dez. 2011. http://revista.anphlac.org.br/index.php/revista 
Cidade do México, eram movidos por agentes da CIA e de Mao Tsé-Tung! Ao recuperar a dimensão ocidental do movimento estudantil, o poeta afirma que tais movimentos não representaram um recrudescimento da luta de classes, mas sim a revolta de um determinado segmento que as sociedades tecnológicas haviam colocado à margem. Eram justamente os estudantes, que, nas sociedades avançadas, contavam com uma estrutura universitária complexa, sendo colocados numa situação peculiar:

(...) durante los largos años que pasan aislados en universidades y escuelas superiores, los muchachos y las muchachas viven en una situación artificial, mitad como reclusos privilegiados y mitad como irresponsables peligrosos. Añádase la aglomeración extraordinaria en los centros de estudio y otras circunstancias bien conocidas y que operan como factores de segregación: seres reales en un mundo irreal. Es verdad que la enajenación juvenil no es sino una de las formas (y de las más benévolas) de la enajenación que impone a todos la sociedad tecnológica. También lo es que, debido a la irrealidad misma de su situación, habitantes de una suerte de laboratorio en donde no rigen del todo las reglas de la sociedad de afuera, los estudiantes pueden reflexionar sobre su estado y asimismo, sobre el del mundo que los rodea. La Universidad es, a un tiempo, el objeto y la condición de la crítica juvenil. ${ }^{11}$

Ainda segundo Paz, outro elemento universal dos movimentos de contestação de 1968 foi a atitude diante da perspectiva do futuro projetada pelas concepções utópicas modernas, pois, para além dos objetivos imediatos e circunstanciais dos movimentos estudantis, os manifestantes opunham o presente versus o fantasma implacável do futuro pré-estabelecido das sociedades modernas. Como disse o próprio poeta: "El progreso ha poblado la historia de las maravillas y los monstruos de la técnica pero no ha deshabitado la vida de los hombres. Nos ha dado más cosas, no más ser". ${ }^{12}$ Inseridos na mesma tradição iniciada por William Blake e pelos poetas surrealistas que concebiam o homem como um ser que deseja e não como um ser que trabalha, os estudantes, a partir de 1968, colocaram a palavra prazer (uma palavra proibida) no centro da vida contemporânea, em vários lugares do mundo ao mesmo tempo:

Cuando digo placer no pienso en la elaboración de un nuevo hedonismo ni en el regreso a la antigua sabiduría sensual - aunque lo primero no sea desdeñable y lo segundo sea deseable - sino en la revelación de esa mitad oscura del hombre que ha sido humillada y sepultada por las morales del progreso: esa mitad que se revela en las imágens del arte y del amor. La definición del hombre como un ser que trabaja debe ser cambiada por la del

\footnotetext{
${ }^{11}$ PAZ, Octavio. Posdata. In: El peregrino en su pátria, história y política de México. 3 ed. Ciudad de México: Ed. Fondo de Cultura Económica, 1992, p. 256.

${ }^{12}$ Ibid., p. 258.
}

Revista Eletrônica da ANPHLAC, n.11, p. 40-58, jul./dez. 2011. http://revista.anphlac.org.br/index.php/revista 
hombre como un ser que desea. Esa es la tradición que va de Blake a los poetas surrealistas y que los jovenes recogen. ${ }^{13}$

Os movimentos estudantis, então, no contexto do ano de 1968, possuem, ao menos para Octavio Paz, algumas características comuns na Europa e nos EUA, que são fruto das contradições do processo de mundialização do capitalismo, também sentido nas sociedades latino-americanas e nos países do Leste europeu e ex-URSS. A situação mexicana, porém, é bastante singular. O México pós-revolução constitui uma sociedade que passou por um processo muito rápido de modernização e teve um desenvolvimento econômico excepcional a partir do final dos anos 30, por isso exige um tratamento bem particular, mesmo no contex to latino-americano:

Pero la rebelión juvenil mexicana fue singular, como el país mismo. No hay ningún dudoso nacionalismo en mi observación; México es una nación que, dentro de la civilización occidental, ocupa una posición excéntrica: "castellana rayada de azteca", decía López Velarde; asimismo, dentro de América Latina, su situación histórica es única: México vive un periodo posrevolucionario, en tanto que la mayoría de los países atraviesan una etapa prerrevolucionaria. (...) Después de un prolongado y sangriento periodo de violencia, la Revolución Mexicana logró crear instituciones originales y un Estado nuevo. ${ }^{14}$

Para Octavio Paz, os estudantes mexicanos não propunham a transformação violenta nem revolucionária da sociedade. Tampouco tinha a coloração "hedonista" de alguns movimentos da época; tratava-se, na verdade, de um movimento reformista e democrático, segundo o poeta mexicano. Como afirma Silvia Cezar Miskulin, o movimento estudantil no México, diferentemente dos ocorridos em outras partes do mundo, como o Maio Francês, por exemplo, não propunha nenhuma reivindicação "acadêmica". ${ }^{15}$ A sua principal reivindicação, segundo Octavio Paz, era o fim do regime de exceção instituído em 1929 pelo Partido Nacional Revolucionário (PNR) — PRM, em 1934, na gestão de Lázaro Cárdenas, e PRI, em 1946 - , que permaneceu no poder até julho de $2000 .{ }^{16}$ Para Paz, os estudantes, com suas reivindicações, arrancaram as

\footnotetext{
${ }^{13}$ PAZ, Octavio. Posdata. In: El peregrino en su pátria, história y política de México. 3 ed. Ciudad de México: Ed. Fondo de Cultura Económica, 1992. p. 258.

${ }^{14}$ Ibid., p. 261.

${ }^{15}$ Ver MISKULIN, Silvia Cezar. A repercussão do movimento estudantil de 1968 no México. In: Encontro Internacional da ANPHLAC, 8., 2008,Vitória, Anais eletrônicos... Vitória: ANPHLAC, 2008. p. 3.

${ }^{16}$ Segundo Paz, as petições dos estudantes eram moderadas e incluíam: fim do artigo penal que punia "delitos de opinião", liberdade a vários presos políticos, destituição do chefe de polícia e o início de um diálogo público entre os estudantes e o governo, como preâmbulo de um diálogo maior entre a população civil $\mathrm{e}$ as autoridades.
}

Revista Eletrônica da ANPHLAC, n.11, p. 40-58, jul./dez. 2011.

http://revista.anphlac.org.br/index.php/revista 
máscaras do governo: "la cárcel de palabras y conceptos en que el gobierno se ha cerrado, todas esas fórmulas se condensan en esa grotesca expresión con que la familia oficial designa al partido único: el Instituto Revolucionario". ${ }^{17}$ Não somente Octavio Paz, mas outros intelectuais "independentes", como Carlos Monsivais, Daniel Cosío Villegas, Julio Scherer García, Carlos Fuentes e Gabriel Zaid, repudiaram, na imprensa, a brutal repressão do governo do PRI na praça das três culturas. ${ }^{18}$

O que é preciso compreender é o significado da violência do governo contra os estudantes. Assim, para explicar o massacre, Octavio Paz remete-se à história da Revolução Mexicana e os motivos que levaram à permanência do PRI no poder, entre 1929 e 2000. Contudo, uma análise usual, que considere apenas as questões econômicas, políticas e sociais, segundo o poeta, não explica o conflito. Nesse sentido, ele recupera, então, o passado mítico do México, sem excluir as explicações de ordem política, econômica e social, como veremos a seguir.

Uma vez formulado nosso problema, cabe, neste artigo, recuperarmos os argumentos do poeta mexicano no ensaio Posdata e discutir seu posicionamento e a perspectiva histórica a partir da qual ele pensou um acontecimento situado no seu próprio tempo. Iremos, ainda, estabelecer algumas conexões e alguns pontos de contato entre as interpretações de Octavio Paz sobre o passado histórico e as obras de alguns historiadores, que, de certo modo, também refletiram sobre temas e questões análogas. Partimos da premissa de que a reflexão sobre a violência no México requer, antes, a recuperação desses argumentos em Posdata, para que não interpretemos de modo apressado e superficial as ideias de Paz incorrendo, assim, em simplificações grosseiras sobre seus pontos de vista, que, muitas vezes, graças às polêmicas geradas em torno de suas posições políticas controversas, tendem a rotular seu pensamento como "liberal" ou "neoliberal", sem antes procurar entender como pensava o poeta mexicano. ${ }^{19}$

Consoante com as interpretações mais atualizadas da história das revoluções e com a reflexão sobre a burocratização da URSS empreendida por Lefort e Castoriadis, Paz afirma que o regime criado pela Revolução Mexicana desembocou numa ditadura

\footnotetext{
${ }^{17}$ PAZ, Octavio. Posdata. In: El peregrino en su pátria, história y política de México. 3 ed., Ciudad de México: Ed. Fondo de Cultura Económica, 1992. p. 265.

${ }^{18}$ MISKULIN, Silvia Cezar. Op. cit., p. 6.

${ }^{19}$ Gostaríamos de ressaltar que se, em vários momentos neste artigo, estabelecemos certas conexões entre as proposições de Octavio Paz sobre o massacre de Tlatelolco e as obras de alguns historiadores que refletiram sobre o México e a história política, não o fazemos para legitimar as afirmações de Paz à luz da historiografia, mas, sim, para buscar compreender melhor a relação entre o ensaio escrito por um poeta e os textos desses historiadores que pensaram sobre temas correlatos.
}

Revista Eletrônica da ANPHLAC, n.11, p. 40-58, jul./dez. 2011.

http://revista.anphlac.org.br/index.php/revista 
revolucionária e o partido da revolução se transformou numa burocracia instituída por um partido único. Para Octavio Paz, a petrificação do PRI no poder criou, então, condições para o aparecimento de uma burocracia política, constituída em partido estatal e composta por especialistas em manipulação de massas. Contudo, há ainda os traços específicos da história mexicana e o passado pré-hispânico que precisam ser considerados.

Para compreender a hegemonia do PRI desde uma perspectiva histórica, Octavio Paz reporta-se às sociedades da Mesoamérica antes da conquista e ao passado précolombiano, assumindo-o como um arquétipo inconsciente ou uma permanência cultural. $^{20}$ A recuperação do passado asteca - tomado como um tempo que "não transcorre", ou que transcorre "bem mais devagar" - permitiria, segundo o poeta, caracterizar o funcionamento do PRI a partir do símbolo da pirâmide na cultura mexicana, em que o partido expressaria determinada representação imaginária do poder:

Hecho a la imagen de la realidad política y social de México, el PRI es una burocracia jerárquica, una verdadera pirámide. Ahora bien, además de constituir una realidad social y política, esta pirámide encarna una realidad imaginaria; sin cesar de ser realidades políticas, el PRI y el Presidente son proyeciones míticas, formas en las que se condensa la imagen que nos hemos hecho del poder. ${ }^{21}$

A perspectiva de Paz situa-se distante de uma visão estritamente institucional ou condicionada às estruturas econômicas, que buscam entender a história política a partir dessas determinações. Ao mesmo tempo, coloca-se ao lado da revisão historiográfica sobre a história e os imaginários sociais, proposta por autores como Baczko, e da obra de Castoriadis e Lefort, que visa uma compreensão do político que recupere as realidades psíquicas, históricas e culturais, irredutíveis aos modelos abstratos de interpretação produzidos pela sociologia e pela historiografia tradicional, demasiadamente presas a esquemas de análise muito rígidos.

\footnotetext{
${ }^{20}$ Segundo Miguel León-Portilla, a expressão Mesoamérica designa a região em que floresceu a alta cultura indígena do México Central e Meridional, no território contíguo aos países do norte da América Central e Meridional. Hoje a Mesoamérica compreende os seguintes países: México, Guatemala, El Salvador, Honduras e, em menor grau, a Nicarágua e a Costa Rica. “(...) É, talvez, a maior diversidade ecológica e geográfica do mundo, em que se desenvolveram as altas culturas." LEÓN-PORTILLA, Miguel. A Mesoamérica antes da conquista. In: BETHELL, Leslie. A América Latina Colonial. São Paulo: EDUSP; Brasília: Fundação Alexandre Gusmão, 1998. v. I.

${ }^{21}$ PAZ, Octavio. Posdata. In: El peregrino en su pátria, história y política de México. 3 ed., Ciudad de México: Ed. Fondo de Cultura Económica, 1992. p. 268.
}

Revista Eletrônica da ANPHLAC, n.11, p. 40-58, jul./dez. 2011. http://revista.anphlac.org.br/index.php/revista 
O ensaio Postdata foi escrito em 1969, ou seja, em pleno debate sobre o "subdesenvolvimento da América Latina". Mas hoje, como afirma Paz, o debate se traduz na "necessidade de inserir a porção mais pobre do mundo no mercado mundial e nos padrões de consumo do mundo civilizado". Tal perspectiva, segundo ele, expressa a incapacidade de pensarmos projetos de desenvolvimento econômico que correspondam ao contexto histórico, psíquico e cultural latino-americano:

no hemos sido capaces de crear modelos de desarrollo viables y que correspondan a lo que somos. El desarrollo ha sido, hasta ahora, lo contrario de lo que significa esa palabra: extender lo que está arrollado, desplegarse, crecer libre y armoniosamente. El desarrrollo ha sido una verdadera camisa de fuerza. ${ }^{22}$

Ao estabelecer a divisão entre o México desenvolvido e o subdesenvolvido, esse debate em torno do termo "subdesenvolvido" pode ser aplicado em determinados campos, como, por exemplo, a saúde e a educação. É preciso, porém, considerar um outro México distinto, conforme afirma Paz,que não é apreendido através das definições de moderno ou desenvolvido. Em Posdata e outros ensaios, Octavio Paz busca decifrar esse outro México, constituído de realidades compostas por diferentes estratos que, alternadamente, se ocultam e se revelam. Para o poeta mexicano, o passado é, então, expressão da otredad, como se fosse "a sombra com a qual nos confrontamos internamente todos os dias", como algo que não está nem dentro nem fora e que a arte e a poesia conseguem expressar. Como diz o poeta, o passado é um presente oculto, ou uma realidade escondida e que, em determinado momento, reaparece - mas não se trata de um tempo que "já passou", supostamente com datas e personagens e tudo o mais que denominamos "história". Ao contrário, ele é algo semelhante a uma realidade inconsciente. A poesia permite, segundo Paz, acessar um tempo que passa sem passar totalmente, ou um presente perpétuo em rotação. Como em uma montagem cinematográfica, os elementos na poesia são combinados sempre de maneira distinta:

La historia de cada pueblo contiene ciertos elementos invariantes o cuyas variaciones, de tan lentas, resultan imperceptibles. ¿Qué sabemos de esos invariantes y de las formas en que asocian o separan? Por analogía con lo que ocurre en otros dominios, vislumbramos que su modo de operación es la combinación de unos cuantos elementos; como en el caso de los procesos biológicos, el montaje cinematográfico o las asociaciones verbales distintas y únicas - o sea: historia. Pero es engañoso hablar de elementos invariantes como si se tratase de realidades aisladas y con vida propia: aparecen siempre

\footnotetext{
${ }^{22}$ Ibid., p. 274.
}

Revista Eletrônica da ANPHLAC, n.11, p. 40-58, jul./dez. 2011. http://revista.anphlac.org.br/index.php/revista 
en relación unos con los otros y no se definen como elementos sino como partes de una combinatoria. ${ }^{23}$

Como um passado mal resolvido e que sempre retorna para nos assombrar, afirma Paz, o massacre dos estudantes, no dia 2 de outubro de 1968, expressa uma tensão entre um México que tentou resolver seus problemas políticos e sociais com a Revolução de 1910 e o outro México - um país violento e injusto que efetivamente existe desde a Conquista, ou até antes. Para o poeta, a otredad da sociedade mexicana seria, então, uma realidade dual que não é externa, ou seja, um México interior, e qualquer tentativa de extirpá-lo poderia mutilar a própria sociedade.

O massacre ocorrido na Praça de Tlatelolco (antigo local onde eram realizados os sacrifícios astecas) foi, segundo Paz, a expressão simbólica da história "subterrânea" e "invisível" do México:

lo que se desplegó ante nuestros ojos fue un acto ritual: un sacrifício. Vivir la historia como un rito es nuestra manera de asumirla; si para los españoles la Conquista fue una hazaña, para los índios fue un rito, la representación humana de una catástrofe cósmica. Entre estos extremos, la hazaña y el rito, han oscilado siempre la sensibilidad y la imaginación de los mexicanos. ${ }^{24}$

Acontecimentos como o massacre da Praça de Tlatelolco são a representação de uma história “oculta” ou a manifestação visível de uma realidade escondida:

\begin{abstract}
Vivimos la historia como si fuera una representación de enmascarados que trazan sobre el tablado figuras enigmáticas (...) nos escapa el significado de la pieza que representamos. ¿Alguien lo sabe? Nadie conoce el desenlace final de la historia porque su fin es también el fin del hombre. ${ }^{25}$
\end{abstract}

A história que vivemos é uma tradução da tradução, isto é, uma escritura em que lemos e traduzimos as metamorfoses da história invisível. Jamais leremos o texto original; cada versão é provisória, o texto muda incessantemente e toda tradução é uma criação. Segundo Octavio Paz, na tarde do massacre dos estudantes a história visível desdobrou a história invisível do outro México à maneira de um códice pré-colombiano.

Para o poeta, a metáfora da pirâmide e o ritual do sacrifício são permanências da cultura pré-colombiana na sociedade mexicana. Na cultura asteca, diz ele, a pirâmide

\footnotetext{
${ }^{23}$ PAZ, Octavio. Posdata. In: El peregrino en su pátria, história y política de México. 3 ed., Ciudad de México: Ed. Fondo de Cultura Económica, 1992. p. 276-77.

${ }^{24}$ PAZ, Octavio. Posdata. In: El peregrino en su pátria, história y política de México. 3 ed., Ciudad de México: Ed. Fondo de Cultura Económica, 1992. p. 278.

${ }^{25}$ Ibid., p. 278.
}

Revista Eletrônica da ANPHLAC, n.11, p. 40-58, jul./dez. 2011.

http://revista.anphlac.org.br/index.php/revista 
mesoamericana é um espaço, uma plataforma-santuário, o lugar de aparição dos deuses e o altar do sacrifício. A pirâmide é um arquétipo arcaico do mundo, uma metáfora geométrica do cosmos: "Un edificio hecho de tiempo: lo que fue, lo que será, lo que está siendo (...) punto de convergencia entre el mundo humano y el divino; tiempo, es el centro del movimiento, el fin y el principio de las eras: presente eterno de los dioses". ${ }^{26}$ Nesse sentido, a pirâmide assegura a continuidade do tempo humano e cósmico pelo sacrifício. Na pirâmide, segundo o poeta mexicano, se materializa a metáfora do mundo como uma montanha e a metáfora da montanha como doadora de vida. A plataformasantuário da pirâmide é o teatro dos deuses e seu campo de jogo. Os deuses jogam com o tempo, e seu jogo é a criação/destruição dos mundos. Segundo Paz, o jogo dos deuses astecas culmina com um sacrifício, que é, em si, a criação do mundo:

La destrucción creadora de los dioses es el modelo de los ritos, las ceremonias y las fiestas de los hombres: sacrificio es igual a destrucción productiva. Para los antíguos mexicanos la danza era sinónimo de penitencia. Parece extraño pero no lo es: danza es primordialmente rito y éste es ceremonia que reproduce la creación del mundo por los dioses en un juego que es la destrucción creadora. ${ }^{27}$

Para Octavio Paz, a equação dança $=$ sacrifício repete-se na simbologia da pirâmide, como uma plataforma que representa o espaço sagrado onde se desdobra a dança dos deuses, em um jogo criador de movimento. O lugar da dança, diz Paz, é simbolicamente o lugar do sacrifício. O mundo da política e o da religião tornam-se, assim, análogos:

para los aztecas el mundo de la religión: la danza celeste que es destrucción creadora es asimismo guerra cósmica; esta serie analógica divina se proyecta en otra terrestre: la guerra ritual (o 'guerra florida') es el doble de la danza guerrera de los dioses y culmina en el sacrificio de los prisioneros de guerra. $^{28}$

Explicitando seus vínculos com a psicanálise, Octavio Paz fala de um modelo inconsciente de representação do poder que se perpetuou: a pirâmide e o sacrifício. A pirâmide é o tempo petrificado, é o lugar do sacrifício dos prisioneiros de guerra, é a imagem do Estado asteca. A missão do Estado é assegurar a continuidade do culto solar,

\footnotetext{
${ }^{26}$ Ibid., p. 280.

${ }^{27}$ PAZ, Octavio. Posdata. In: El peregrino en su pátria, história y política de México. 3 ed., Ciudad de México: Ed. Fondo de Cultura Económica, 1992. p. 280.

${ }^{28}$ Ibid., p. 281.
}

Revista Eletrônica da ANPHLAC, n.11, p. 40-58, jul./dez. 2011.

http://revista.anphlac.org.br/index.php/revista 
fonte de vida universal, pelo sacrifício dos prisioneiros de guerra. Como a metáfora da roda do tempo, o povo asteca se identifica com o culto solar. Trata-se, na verdade, de uma representação da nação asteca e que permaneceu, de certa maneira, ao longo do México colonial e contemporâneo:

\begin{abstract}
El pueblo mexica se identifica con el culto solar: su dominación es semejante a la del sol que cada día nace, combate y muere y renace. La pirámide es el mundo y el mundo es México-Tenochtitlan: deificación de la nación azteca por su identificación con la imagen ancestral del cosmos, la pirámide. Para los herederos del poder azteca, la conexión entre los ritos religiosos y los actos políticos de dominación desaparece pero, como se verá en seguida, el modelo inconsciente del poder siguió siendo el mismo: la pirámide y el sacrificio. $^{29}$
\end{abstract}

Expressão do tempo mítico, a metáfora da pirâmide, segundo Paz, tornou-se um "modelo inconsciente" ou uma expressão imaginária da sociedade mexicana sobre si mesma. Sob esse aspecto, então, a geografia do México possui a forma de uma pirâmide; forma peculiar que tem uma enorme carga simbólicae, de acordo com Octavio Paz, precisa ser interpretada. ${ }^{30}$ Não se trata, porém, de um caso específico da geografia do México. Segundo Paz, as geografias são simbólicas e os espaços físicos resolvem-se

\footnotetext{
${ }^{29}$ PAZ, Octavio. Posdata. In: El peregrino en su pátria, história y política de México. 3 ed., Ciudad de México: Ed. Fondo de Cultura Económica, 1992. p. 282.

${ }^{30}$ Segundo Miguel León-Portilla, os Olmecas foram os primeiros a erigir grandes complexos de construções para fins religiosos: pirâmides rebocadas de barro, túmulos circulares e alongados, altares entalhados na pedra, grandes compartimentos de pedra, fileiras de colunas de basalto, tumbas, sarcófagos, estelas, colossais cabeças de basalto. As cerimônias eram realizadas ao ar livre, numa grande praça pública. Os Olmecas adoravam um deus-jaguar onipresente e divindades como pássaros fantásticos e serpentes, com formas meio humanas. A cultura olmeca se difundiu por regiões diferentes, tornando-se uma cultura matriz que transmitia seu universo religioso e arquitetônico, principalmente as pirâmides. Através do comércio e de um empenho religioso missionário, suas influências aparecem em outras regiões do Golfo do México e do planalto central. Por volta de 600 a. c., as aldeias olmecas cresceram dando lugar a centros maiores. Teotihuacán, a "metrópole dos deuses", constitui o melhor exemplo do apogeu da civilização clássica no planalto central. Era uma verdadeira cidade: extensos bairros, onde os membros da comunidade tinham suas residências, que rodeavam o centro administrativo e religioso mais denso. As pirâmides, os templos, os palácios e a maioria das casas dos governantes ou dos membros da nobreza eram decorados de pinturas murais nas quais estavam representados os deuses, pássaros fantásticos, serpentes, jaguares e várias plantas. Os teotihuacanos cultuavam diversos deuses invocados posteriormente por outros povos de língua nahuat: Tlaloc Chalchiuhtliue, senhor e senhora das águas; Quetzacóaltl, a serpente emplumada; Xiuhtecuhtli, senhor do fogo; Xochipilli, príncipe das flores. Havia ainda os povos que tinham se localizado nas fronteiras do norte de Teotihuacán. Esses povos da fronteira do norte, mais tarde, vieram a se chamar Toltecas e, ao constatar a ruína de Teotihuacán, decidiram "retornar" à sua terra de origem cultural, o México central, e se fixaram em Tula, um local a $80 \mathrm{~km}$, ao norte da atual cidade do México. Uma figura central na história dos toltecas é o famoso Quetzalcoaltl, uma espécie de herói cultural, que tirou seu nome de um deus (a serpente emplumada) cultuado desde os dias de Teotihuacán. Numerosos textos falam de seu nascimento, vida e feitos prodigiosos. Tornou-se o deus e sacerdote dos Totelcas e de outros povos. Não está claro o que provocou a queda de Tula por volta de 1150. Mas a ruína dos toltelcas significou a difusão de sua cultura entre diversos povos distantes.
}

Revista Eletrônica da ANPHLAC, n.11, p. 40-58, jul./dez. 2011. http://revista.anphlac.org.br/index.php/revista 
em arquétipos geométricos, que são formas emissoras de símbolos. ${ }^{31}$ Para o poeta, cada história é uma geografia que se transforma em uma geometria de símbolos:

India es un cono invertido, un arból cuyas raíces se hunden en el cielo; China es un imenso disco -vientre, ombligo y sexo del cosmos-; México se levanta entre los mares como una enorme pirámide trunca: sus cuatro costados son los cuatro puntos cardinales, sus escaleras son los climas de todas las zonas, su alta meseta es la casa del sol y de las constelaciones. ${ }^{32}$

Se a geografia do México representa a forma piramidal e o Valle de Anáhuac (local da antiga metrópole México-Tenochititlán, onde foi construída a capital que deu nome ao país), tal fato, para Octavio Paz, não pode passar despercebido. Ora, a capital deu nome ao país, ao contrário do que acontece na maioria dos países, onde o nome da capital costuma ser distinto. A distinção torna-se imperativa, pois a antiga capital, em geral, trata-se da velha metrópole com uma história própria e de dominação sobre outras cidades. ${ }^{33}$ Ele cita os seguintes exemplos: Roma/Itália, Paris/França, Tóquio/Japão, Teerã/Irã, Londres/Inglaterra, etc. Segundo Octavio Paz, nem sequer os centralistas castelhanos atreveram-se a desrespeitar a regra diferenciando também o nome da capital ao do país: Madrid/Espanha.

O próprio nome México-Tenochtitlán evoca a ideia da dominação asteca. Uma das chaves da história mexicana, afirma Paz, é o fato de que o país leva o nome da antiga cidade, capital do Império asteca e opressora das demais etnias existentes na região. Como se houvesse uma ligação entre a antiga dominação asteca, encarnada no poder imperial da elite tlatoanis (grupo de aristocratas que compunham a classe

\footnotetext{
${ }^{31} \mathrm{Ou}$ seja, a paisagem é histórica e converte-se em hieróglifo, em texto cifrado, e as oposições entre mar e terra, ilha e continente, montanha e plano, selva e deserto são símbolos de oposições históricas entre diferentes sociedades, culturas e civilizações. Podemos recordar aqui as oposições entre o litoral e o sertão, como um elemento importante para se compreender a guerra de Canudos, tal como demonstra Euclides da Cunha. Sobre esse tema ver: GÁRATE, Miriam. Civilização e barbárie n'os Sertões: entre Domingos Faustino Sarmiento e Euclides da Cunha. Campinas: Mercado das Letras; São Paulo: FAPESP, 2001.

${ }^{32}$ PAZ, Octavio. Posdata. In: El peregrino en su pátria, história y política de México. 3 ed., Ciudad de México: Ed. Fondo de Cultura Económica, 1992. p. 279.

${ }^{33}$ Com a decadência dos toltecas, os mexicas (astecas) ocuparam o seu território, enfrentando vários obstáculos até se fixarem na ilha de Tenochtitlán, entre os lagos que cobriam uma grande parte do vale do México. Uma das realizações dos mexicas, no seu apogeu político e cultural, mais ou menos nos últimos 60 anos antes do contato com os europeus, foi ter forjado uma imagem de suas próprias origens, desenvolvimento e identidade. Por volta de 1430, Itzcoatl ordenou a queima dos livros antigos, tanto os anais quanto os de conteúdo religioso. No lugar deles, foi desenvolvida e imposta uma nova tradição que transmitia a imagem do passado adequada às exigências e ideais do grupo cuja dominação estava em processo de rápida expansão. Ver: LEÓN-PORTILLA, Miguel. A Mesoamérica antes da Conquista. In: BETHELL, Leslie. A América Latina Colonial. São Paulo: EDUSP ; Brasília: Fundação Alexandre Gusmão, 1998. v. I, p. 37-42.
}

Revista Eletrônica da ANPHLAC, n.11, p. 40-58, jul./dez. 2011. http://revista.anphlac.org.br/index.php/revista 
governante no Império asteca), o poder dos vice-reis espanhóis do período colonial e o poder dos presidentes mexicanos eleitos pelo PRI:

\begin{abstract}
Haber llamado al país entero con el nombre de la ciudad de sus opresores es una de las claves de la historia de México, la historia no escrita y nunca dicha. La fascinación que han ejercido los aztecas ha sido tal que ni siquiera sus vencedores, los españoles, escaparon de ella: cuando Cortés decidió que la capital del nuevo reino se edificaría sobre las ruinas de MéxicoTenochtitlán, se convirtió en el heredero y sucesor de los aztecas. A pesar de que la conquista española destruyó el mundo indígena y construyó sobre sus restos otro distinto, entre la antigua sociedad y el nuevo orden hispánico se tendió un hilo invisible de continuidad: el hilo de dominación. Ese hilo no se ha roto: los virreyes españoles y los presidentes mexicanos son los sucesores de los tlatoanis aztecas. ${ }^{34}$
\end{abstract}

Sob a perspectiva de Paz, a pirâmide e suas implacáveis hierarquias, com os mandantes e a plataforma do sacrifício em seu topo, transformam-se, então, num arquétipo religioso-político do México pré-colombiano. Na representação do poder na história do México pós-conquista, estabelece-se uma continuidade política entre o senhor asteca e o poder do vice-rei espanhol. No âmbito das representações religiosas, a continuidade se materializa no culto à Virgem de Guadalupe:

La aparición de la virgen de Guadalupe sobre las ruinas de un santuario consagrado a la diosa Tonantzin es el ejemplo central, aunque no es el único, de esta relación entre los dos mundos, el indígena y el colonial. En un auto sacramental, de Sor Juana, el divino Narciso, la antígua religión precolombina, a pesar de sus ritos sangrientos, aparece como una prefiguración de la llegada del cristianismo a tierras mexicanas. ${ }^{35}$

A representação da Independência do México, segundo Paz, também seria percebida na sociedade mexicana como uma volta ao mundo pré-hispânico. Como se a Revolução de Independência viesse reforçar o processo de identificação sentimental com o período anterior à Conquista espanhola. Nessa representação, a Cidade do México passou a ser vista como a continuidade e a afirmação da antiga metrópole asteca. Com a Revolução Mexicana, a identificação com o passado pré-hispânico foi fortalecida. Para Octavio Paz, essa identificação com o passado asteca, reforçou, por sua vez, o mito da pirâmide e do sacrifício na sociedade mexicana contemporânea:

\footnotetext{
${ }^{34}$ PAZ, Octavio. Posdata. In: El peregrino en su pátria, história y política de México. 3 ed., Ciudad de México: Ed. Fondo de Cultura Económica, 1992. p. 283.

${ }^{35}$ Ibid., p. 285.
}

Revista Eletrônica da ANPHLAC, n.11, p. 40-58, jul./dez. 2011.

http://revista.anphlac.org.br/index.php/revista 
Del mismo modo que la Roma cristiana prolongaba, ratificándola, a la Roma pagana, la nueva ciudad de México era la continuación, la rectificación y, finalmente, la afirmación da metrópoli azteca. La Independencia no alteró radicalmente esta concepción: se consideró que la Colonia española había sido una interrupción de la historia de México y que, al liberarse de la dominación europea, la nación restablecía sus libertades y reanudaba su tradición. (...) Desde la Independencia el proceso de identificación sentimental con el mundo prehispánico se acentúa hasta convertirse, después de la Revolución, en una de las características más notables del México moderno. Lo que no se ha dicho es que los mexicanos, en su inmensa mayoría, han hecho suyo el punto de vista azteca y así han fortificado, sin saberlo, el mito que encarnan la pirámide y su piedra de sacrifícios. ${ }^{36}$

Durante a hegemonia asteca, após a queda da cidade de Tula, os militares, os sacerdotes e a população como um todo acreditavam ser os instrumentos de uma missão divina: servir, preservar e estender o culto solar, visando à manutenção da ordem cósmica. Conforme diz Octavio Paz, o culto exigia alimentar os deuses com sangue humano para assegurar a marcha do universo - ideia sublime e aterradora:

la sangre como sustancia animadora del movimiento de los mundos, un movimiento análogo al de la danza y de la guerra. Danza guerrera de los astros y lo planetas, danza de la destrucción creadora. Cadena de equaciones y trasformaciones: $\quad$ rito $\rightarrow$ danza $\rightarrow$ guerra $\rightarrow$ ritual $\rightarrow$ sacrificio $\quad(.$.$) el sol$ guerrero que bebe sangre y cada día salva al mundo de la destrucción definitiva. Sol polémico, sol del movimiento: guerras, temblores de tierra, eclipses, danza del cosmos. ${ }^{37}$

\footnotetext{
${ }^{36}$ PAZ, Octavio. Posdata. In: El peregrino en su pátria, história y política de México. 3 ed., Ciudad de México: Ed. Fondo de Cultura Económica, 1992. p. 284-5. É preciso ressalvar que a civilização asteca não representou o apogeu das sociedades pré-cortesianas. Segundo Paz, consoante com as interpretações mais atualizadas sobre o México pré-colombiano, o grande período criador dessas civilizações está situado antes da hegemonia asteca: "En culaquier caso, la fase creadora de Mesoamérica - que casi todos los arqueólogos actuales, en general, llaman, no sé si muy exactamente, 'período de las grandes teocracias' - termina hacia el siglo IX. La extrordinaria fecundidad artísitca y intelectual de esa etapa se debe, a mi manera de ver, a la coexistencia en distintas zonas del país de varias culturas originales, aunque pobremente surgidas de un tronco común: mayas, zapotecas, la gente de Teotihuacan, a la gente de El Tajín. No hubo hegemonía de un estado sobre los otros sino diversidad y confrontación, ese juego de influencias y creaciones en que consiste finalmente toda creación. Mesoamérica no era una pirámide sino una asemblea de pirámides. Por supuesto, ese periodo no fue una época de paz universal como han dicho con ingenuidad algunos de nuestros arqueólogos. Teocráticas o no, esas ciudades-Estado no eran pacíficas; los muros de Bonampak conmemoran una batalla con su corolario ritual, el sacrificio de los prisioneros, en Teotihuacan aparecen muchos de los símbolos que después figurarián en el culto solar azteca, así como los emblemas de las órdenes militares del águila y el del jaguar y varios indicios de canibalismo ritual. Muchos estudiosos minimizaran estos rasgos de la civilización mesoamericana, tendencia no menos nociva que la aquellos que los exageran. Unos y otros olvidan que la ciencia no tiene por objeto juzgar sino compreender. Mesoamérica, además, no necesita ni apologistas ni detractores." $\mathrm{O}$ segundo período é conhecido pela historiografia como período histórico, foi aquele das grandes hegemonias e iniciou-se com a hegemonia da cidade de Tula e dos toltecas, na região central do México, próximo onde hoje é a capital. Ibid., p. 285-286.

${ }^{37}$ Ibid., p. 287.
}

Revista Eletrônica da ANPHLAC, n.11, p. 40-58, jul./dez. 2011. http://revista.anphlac.org.br/index.php/revista 
Segundo Paz, entre as culturas pré-colombianas, acreditava-se que os astecas eram povos do "quinto sol", destinados, nas mitologias daquelas sociedades, a alimentarem o sol guerreiro, que bebe o sangue oferecido em sacrifício, e, assim, salva o mundo da destruição definitiva. Os astecas se identificavam com os deuses. De acordo com um cronista espanhol da época da Conquista citado por Paz, Frei Bernardino de Sahagún, a crença no deus nacional dos astecas, Huitzilopochtli, pressupunha que o deus era o povo mesmo: "No el pueblo es dios de los demócratas del occidente sino el dios es pueblo: la divinidad encarna en la sociedad y le impone tareas inhumanas, sacrificar y ser sacrificada". ${ }^{38}$ A hegemonia asteca converteu a guerra ritual numa prática constante em que os povos vassalos eram obrigados a realizarem, periodicamente, batalhas campais com os astecas e seus aliados para fornecer cativos destinados ao sacrifício, como se as nações subjugadas fossem uma reserva de alimento sagrado. O ethos asteca, afirma Paz, movia-se entre a religião solar e uma ideologia expansionista — um heroísmo sobre-humano combinado com o realismo político -, a loucura sagrada e a fria astúcia, o sacrifício e a pilhagem.

Para Octavio Paz, México-Tenchtitlán desapareceu, mas, diante de seu corpo caído, aparece um fantasma que habita a história dos mexicanos e o preocupa. A crítica da história do México, então, impõe uma sorte de terapêutica ou uma psicanálise do passado pré-colombiano. Trata-se de realizar a crítica da representação do México como uma pirâmide, que constituía o ponto de vista daqueles que estavam no topo da pirâmide mas que ainda se mantém. Ou seja, a permanência do passado asteca impõe a necessidade da crítica da representação imaginária do México como uma pirâmide: "La crítica de México comienza por la crítica de la pirámide”.

Não devemos confundir a pesquisa sobre a história do político com a intervenção de um poeta no espaço público, que se posicionou sobre determinada questão contemporânea através da publicação de um ensaio que discutia a história política, haja vista que se trata de formas diferentes de interpretar a realidade, construídas a partir de pressupostos e objetivos diversos. Contudo, feita a ressalva, podemos estabelecer uma relação entre o modo como Rosanvallon compreende o papel da história do político e a perspectiva de Paz em Posdata. Se Octavio Paz buscou, em Posdata, entender e denunciar o massacre dos estudantes na Praça de Tlatelolco, elaborando uma reconstituição da "gênese" histórica desse acontecimento, para

\footnotetext{
${ }^{38}$ PAZ, Octavio. Posdata. In: El peregrino en su pátria, história y política de México. 3 ed., Ciudad de México: Ed. Fondo de Cultura Económica, 1992. p. 287.
}

Revista Eletrônica da ANPHLAC, n.11, p. 40-58, jul./dez. 2011.

http://revista.anphlac.org.br/index.php/revista 
Rosanvallon o papel da história do político é semelhante ao procedimento do poeta mexicano:

\begin{abstract}
A história [do político] assim concebida é o laboratório em atividade do nosso presente e não apenas a iluminação de seu pano de fundo. Por essa razão, a atenção aos problemas contemporâneos mais explosivos e mais urgentes não poderia estar dissociada de uma meticulosa reconstrução de sua gênese. Este deve ser o método desenvolvido para dar a profundidade indispensável às análises do político: partir de uma questão contemporânea para reconstruir sua genealogia, antes de fazê-la voltar ao término dessa investigação rica em ensinamentos do passado. É desse diálogo permanente entre o passado e o presente que o processo instituinte das sociedades pode se tornar legível. ${ }^{39}$
\end{abstract}

Segundo Octavio Paz, o massacre dos estudantes foi uma espécie de "sacrifício", e para compreendê-lo precisamos recuperar o passado mexicano anterior à Conquista. Como afirma o poeta, o local do massacre é um local "imantado pela história". Cortés refere-se à praça onde os estudantes foram mortos como a sede de uma casta de mercadores, o último bastião asteca que se entregou após o sítio dos conquistadores à cidade de Tenochtitlan. Nesse local, os missionários católicos também ensinaram as letras clássicas aos membros da nobreza asteca e Sahagún deu início ao estudo de história pré-hispânica. No século XX, segundo o poeta mexicano, a praça teve uma história obscura: foi prisão militar, centro ferroviário e bairro superpovoado. Hoje, ela se chama Praça das Três Culturas, mas continua sendo conhecida por seu antigo nome, Tlatelolco. Isso não se dá por acaso, o 2 de outubro de 1968, dia do massacre, faz parte da história real e simbólica do México: "No es accidental esta preferencia por el antiguo nombre mexica: el 2 de octubre de Tlatelolco se inserta con aterradora lógica dentro de nuestra história, la real y la simbólica". ${ }^{40}$ Se o passado explica o presente e vice-versa, o massacre na praça é a contrapartida, em termos de sangue e sacrifício, da petrificação do PRI no poder, e ambos são projeções do imaginário da sociedade asteca na sociedade mexicana contemporânea.

Para concluir, seria válido acrescentar que, em Posdata, a ênfase demasiada no peso do passado pré-hispânico sobre o México contemporâneo está inspirada na antropologia do mito de Lévi-Strauss. ${ }^{41}$ A representação do PRI como um partido

\footnotetext{
${ }^{39}$ ROSANVALLON, Pierre. Por uma história do político. São Paulo: ALAMEDA, 2010. p. 77.

${ }^{40}$ PAZ, Octavio. Posdata. In: El peregrino en su pátria, história y política de México. 3 ed., Ciudad de México: Ed. Fondo de Cultura Económica, 1992. p. 298.

${ }^{41}$ Questão analisada em nossa pesquisa sobre a obra de Octavio Paz como um todo. Ver CRIPA, Ival de Assis. O círculo, a linha e a espiral: temporalidades da poesia e da história na obra crítica de Octavio Paz.
}

Revista Eletrônica da ANPHLAC, n.11, p. 40-58, jul./dez. 2011. http://revista.anphlac.org.br/index.php/revista 
herdeiro do poder dos guerreiros e sacerdotes astecas recupera traços importantes da história política mexicana, mas cria, na obra de Paz, a imagem de que a história é feita apenas de mudanças da elite no poder. Assim como em Braudel, também inspirado em Lévi-Strauss $^{42}$, a permanência das estruturas arcaicas herdadas do período anterior à Conquista do México, exposta na obra de Octavio Paz com ênfase no "tempo longo", impede que o poeta mexicano perceba a história como um campo de possibilidades em que os sujeitos históricos são capazes de superar o peso dessas estruturas arcaicas.

\section{Referências Bibliográficas}

BACZKO, Bronislaw. Los imaginarios sociales. Memorias y esperanzas colectivas. Buenos Aires: Nueva Visión, 1991.

CRIPA, Ival de Assis. O círculo, a linha e a espiral: temporalidades da poesia e da história na obra crítica de Octavio Paz. 2007. Tese (Doutorado em Teoria e História Literária) — Instituto de Estudos da Linguagem, UNICAMP, Campinas, 2007.

Disponível em: http://cutter.unicamp.br/document/results.php?words=cripa DENIS, Benoît. Literatura e Engajamento: de Pascal a Sartre. Bauru, SP : EDUSC, 2002.

DOSSE, François. A história à prova do tempo: da história em migalhas ao resgate do sentido. São Paulo: Editora da UNESP, 2001.

GÁRATE, Miriam. Civilização e barbárie n'os Sertões: entre Domingos Faustino Sarmiento e Euclides da Cunha. Campinas: Mercado das Letras; São Paulo: FAPESP, 2001.

LEDESMA, Xavier Rodrigues. El pensamiento político de Octavio Paz, las trampas de la ideología. Ciudad de México: Plaza y Valdés, 1996.

LEFORT, Claude. A invenção democrática: os limites do totalitarismo. São Paulo: Brasiliense, 1983.

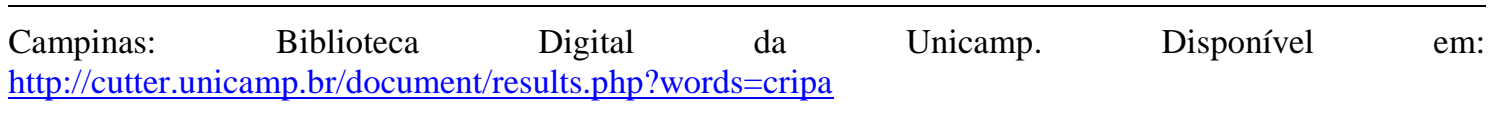

\footnotetext{
42 Segundo François Dosse, para Braudel “(...) a missão de qualquer sociedade é a reprodução de suas estruturas, como ocorre com as 'sociedades frias' de Claude Lévi-Strauss. A ordem em vigor perpetua-se, tornando vãs as tentativas de transformação dos homens. Querer superar esse estado é perda de tempo (...). A longa duração enleia, e o paradoxo aparece manifesto, nunca ressaltado, e o historiador Braudel esvazia a historicidade". DOSSE, François. A história à prova do tempo: da história em migalhas ao resgate do sentido. São Paulo: Editora da UNESP, 2001. p.169.
}

Revista Eletrônica da ANPHLAC, n.11, p. 40-58, jul./dez. 2011.

http://revista.anphlac.org.br/index.php/revista 
LEÓN-PORTILLA, Miguel. A Mesoamérica antes da Conquista. In: BETHELL, Leslie. A América Latina Colonial. São Paulo: EDUSP; Brasília: Fundação Alexandre Gusmão, 1998. v. I.

MISKULIN, Silvia Cezar. A repercussão do Movimento Estudantil de 1968 no México. In: Encontro Internacional da ANPHLAC, 8., 2008, Vitória, Anais eletrônicos... Vitória: ANPHLAC, 2008.

MONSIVAIS, Carlos. El laberinto de la soledad: el juego de espejos. In: Memoria del Coloquio Internacional Por el Laberinto de la soledad a 50 años de su publicación. Anuário da Fundación Octavio Paz, n. 3, Fundación Octavio PazlEFE: Ciudad de México, 2001.

PAZ, Octavio. Posdata. In: El peregrino en su pátria, história y política de México. 3 ed., Ciudad de México: Ed. Fondo de Cultura Económica 1992.

ROSANVAllon, Pierre. Por uma história do político. Trad. Christian Edward Cyril Liynch. São Paulo: Alameda, 2102.

Revista Eletrônica da ANPHLAC, n.11, p. 40-58, jul./dez. 2011.

http://revista.anphlac.org.br/index.php/revista 